\title{
A Pocket Assay Grouting Technology for Rock Burst Control under Huge-Thick Conglomerate
}

\author{
Junwei Shi $\mathbb{D},{ }^{1,2}$ Xiangrui Meng, ${ }^{1}$ Jifang Du, ${ }^{2}$ Yu Dong, ${ }^{2}$ and Ying Wang ${ }^{2}$ \\ ${ }^{1}$ School of Energy and Safety Engineering, Anhui University of Science and Technology, Huainan, China \\ ${ }^{2}$ School of Management Science and Engineering, Shandong Technology and Business University, Yantai, China \\ Correspondence should be addressed to Junwei Shi; 542670686@qq.com
}

Received 26 July 2020; Revised 18 August 2020; Accepted 9 October 2020; Published 29 October 2020

Academic Editor: Xianjie Hao

Copyright (c) 2020 Junwei Shi et al. This is an open access article distributed under the Creative Commons Attribution License, which permits unrestricted use, distribution, and reproduction in any medium, provided the original work is properly cited.

As the carrier of force and energy, large-scale breaking or bending of huge-thick conglomerate tends to induce impact ground pressure in stope and tunnel. The stratum movement under huge-thick conglomerate was studied in this paper, which is mainly based on the key stratum theory for ground control. Based on this theory, the huge-thick conglomerate can be regarded as the main key stratum, and stratum movement or the development of grassroots state under huge-thick conglomerate will affect the structure itself, which may induce rock burst in stope and tunnel. The grouting technology is proved to effectively limit the bending settlement of conglomerate, control stress concentration of conglomerate, and improve the structure of the source of rock burst, which is an effective method for the control of huge-thick conglomerate. In this paper, the optimization of grouting filling material ratio is studied by the orthogonal experiments and the results show that the optimization of material ratio is cement: fly ash: gangue $1: 2.22: 4.44$, concentration $75 \%$. Under such conditions, pumpability and intensity reach the best. Meanwhile, a new technology, called pocket assay grouting technology, is put forward in this paper. It can prevent slurry leakage, protect the environment, and improve the efficiency of slip casting. The application of this technology in Huafeng mine shows that it not only realizes the safe, efficient, and green of coal mine but also provides technical support to control occurrence of rock burst induced by the movement of the huge-thick conglomerate in deep mining.

\section{Introduction}

Rock burst is a big problem in mining engineering which brings a huge threat to mine production and people's life safety [1]. The rock burst induced by overlying rock movement and redistribution of stress field caused by deep mining is one of the most significant deep disasters [2]. The problem has been studied deeply by Guo et al. who found that the conglomerate movement may be an internal cause of rock burst [3]. According to the field observation, the movement of conglomerate is the main force source of rock burst in deep mine and have an influence of the rock burst periodically with the movement. At present, scholars have basically reached a consensus that the movement of superthick conglomerate beds is one of the main causes of rock burst [4-6]. In the process of mining, the separation development of superthick conglomerate layers would occur which has an adverse influence on the mining. To tackle this problem, the grouting technology of the separation zone was explored [7].

Separation grouting and filling technology plays a positive role in controlling the movement of giant thick conglomerate layer and thus controlling the occurrence of rock burst [8]. In the 1960s, filling mining was developed in China. As a key technology of green mining, it can effectively control mining subsidence [9-11]. The movement of coal seam mining process in upper strata could form abscission layer space. The grouting technology is that drilling a hole at an appropriate position from the ground and then the filling slurry will be injected into the abscission layer space through the hole with high pressure. Slurry filling body and fractured rock mass are formed as a whole to support the overlying strata, thus slow the spread of strata movement towards the surface and finally achieve the goal of controlling surface subsidence [12]. In China, since the success of the field tests in Laohutai mine, the grouting technology was popularized 
and applied in more than 10 mines [13]. Compared with the traditional face filling technology, the separation grouting filling technology is completely carried out in the ground drilling, and the grouting system is completely separated from the production system. Therefore, there is no need to change the underground mining technology. The grouting technology is conducive to the realization of efficient and safe coal mining, and opens up a new way for green mining technology.

At present, scholars' research studies on the separation grouting and filling technology mainly focus on the sink reduction mechanism, the grouting technology, the sink reduction effect, and other aspects, which have produced many valuable achievements [14-16]. However, few research studies have been done that the occurrences of rock burst on working face can be reduced from the aspect of controlling the bending and breaking of the overlying superthick conglomerate layer. In view of this, this study tries to explore through the adoption of abscission layer grouting reinforcement technique to limit the movement of the thick conglomerate layer by the study of the mechanism of abscission layer grouting technique, abscission layer grouting filling material proportioning optimization, and abscission layer grouting process and puts forward a new type of pocket assay grouting reinforcement technique to eliminate the induced power of percussive ground pressure. This study will have a positive role on the prevention and treatment of the occurrence of percussive ground pressure at the coal working face.

\section{Study on Mechanism of Rock Burst Prevention and Control by Separating Grouting and Filling}

The concentrated area or source develops and evolves under deep well superthick conglomerate, and rock burst is caused by the violent activities of the main key strata. The bending, breaking, or stress of the overlying main key strata plays a very important role in the occurrence of rock burst [17-20]. The separation grouting filling technology can not only support the upper strata and compact the lower strata but also expand the separation space by increasing the pumping pressure. In this way, the long-term stability of the main key stratum in the overlying strata can be guaranteed, and the energy accumulation and transfer caused by the rupture of the main key stratum can be eliminated, so as to reduce the risk of causing rock burst from the source.

Due to the emergence of a large area of separation space in the lower part of the superthick conglomerate, a high stress concentration circle is formed around the separation layer. The stress was transferred by the rock mass below the conglomerate, and the original supporting pressure was superimposed on the working face and roadway to form an impact stress field, which resulted in the accumulation of a large amount of elastic energy in the coal rock mass around the stope. After the separation grouting, the contact area between the superthick conglomerate and the lower strata increases, and part of the load of the superthick conglomerate is transferred to the lower strata through the backfill, which reduces the stress concentration on the contact surface around the separation layer. At the same time, backfill limits the range of gentle subsidence of superthick conglomerate, reduces the degree of surface rebound, and the binding force of surrounding rock masses on the superthick conglomerate is correspondingly reduced. The stress on the contact surface around the separation layer is significantly reduced compared with that before the filling. Since the backfill transmits the stress to the goaf, the goaf shares part of the load of overlying conglomerate, which reduces the stress concentration of the coal body and reduces the risk of rock burst, as shown in Figure 1.

2.1. The Distribution of Filling Body in the Separation Layer. Coal mine separation grouting filling materials generally choose coal plant fly ash. The physical properties of fly ash are stable, and the price is relatively low [21,22]. Fly ash backfill can usually be defined as an elastoplastic fluid in fluid mechanics. The movement of separation is a dynamic process. With the difference of flow velocity and pressure in the separation, the body of the separation grouting body is different. When the abscission layer grouting body in abscission layer space is precipitated, other pumping slurries under the pressure of pumping will still slurry along the delamination of space development direction, continue to flow extending forward, until the loss after pumping pressure, and stop the flow, segregation precipitation, and a few small solid particles can follow the development, into the new expansion of cracks, as the number of particle sedimentation reaches a certain amount of abscission layer grouting filling experience accumulation into ash dam; abscission layer grouting filling body within the abscission layer distribution form is shown in Figure 2.

2.2. Stress Model of Separation Grouting Backfill. The stress model of the abscission layer grouting filling body is proposed based on the research and application of the rock beam theory [23]. In the process of abscission layer formation, the abscission layer of upper rock layer can be assumed as a clamped beam. The parameter of the clamped beam is uniformly distributed load of $q$, height of $h$, the elastic modulus of $E$, and abscission span for $l$, and both ends of the upper strata fracture of the maximum deflection can be calculated by

$$
y_{a \max }=\frac{q l^{4}}{32 E h^{2}} .
$$

If assuming that the abscission upper rock layer is used as a simply supported beam, the maximum deflection unfractured at both ends of the upper rock layer can be calculated as follows:

$$
y_{b \max }=\frac{5 q l^{4}}{32 E h^{2}} .
$$

If the bending settlement reaches the maximum value, there is no external force to support the upper strata. The stress direction of the backfill in the separation space is 


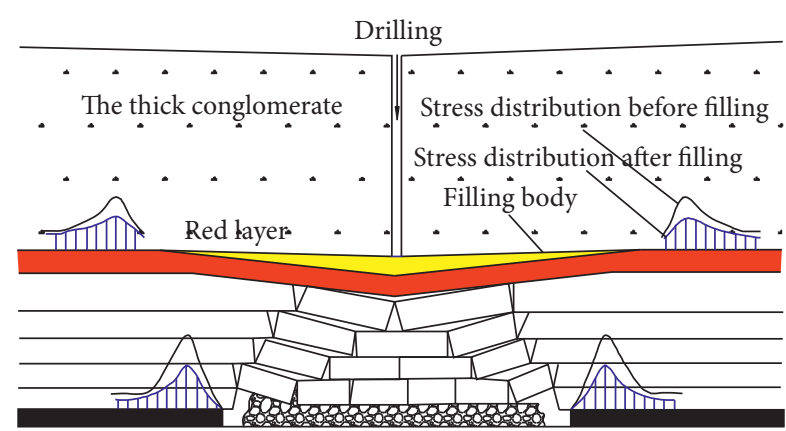

FIGURE 1: Schematic diagram of stress distribution before and after separation grouting.

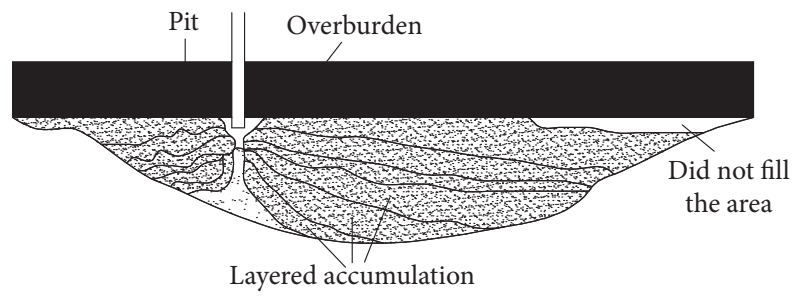

Figure 2: Abscission layer grouting filling body within the abscission layer distribution diagram form.

mainly squeezed by the main overlying key layer and the underlying overlying strata, as shown in Figure 3.

In the process of separating grouting, the upper rock beam, also the main key layer, receives an upward uniformly distributed supporting force from the backfill. For the simple supported beam, the maximum deflection of this supporting force $P$ is

$$
y_{a \max }^{\prime}=\frac{5(q-p) l^{4}}{32 E h^{2}} .
$$

For the clamped beam, the maximum deflection is

$$
y_{b \max }^{\prime}=\frac{(q-p) l^{4}}{32 E h^{2}} .
$$

It can be seen that the deflection of the rock beam under the grouting condition is obviously less than the maximum deflection ratio of the rock beam without grouting. In other words, compared with the maximum deflection ratio of the rock beam without grouting, the deflection of the rock beam under the grouting condition is obviously smaller. Under the influence of the abscission layer grouting filling body, great changes of overburden movement will occur, especially the main key strata movement, such as deformation or fracture, and then the whole movement of overburden rock stress accumulation and redistribution. According to the mechanism of rock bursts start, these changes will eventually limit the occurrence of percussive ground pressure of mining face.

\section{Optimization Test of Separation Grouting Filling Material Ratio}

The performance of grouting filling materials is the key to the success of the separation grouting filling mining

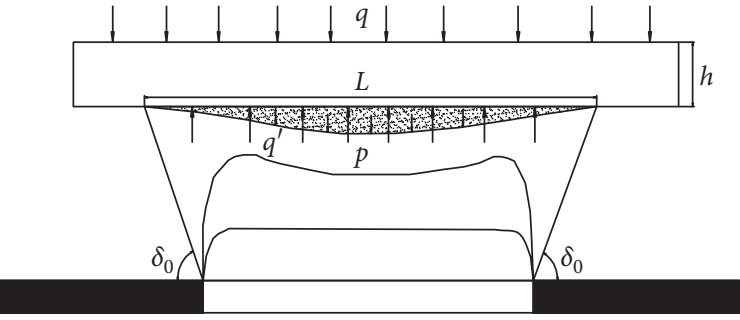

FIGURE 3: Schematic diagram of the stress model of separation grouting backfill. $q$ is the load density of the main critical layer; $p$ is the supporting force of backfill on the main key layer; $q^{\prime}$ is the vertical compressive stress of backfill to the lower rock layer.

technology [24]. Based on the difference of filling materials, the common coal mine grouting and filling mining technologies can be divided into coal gangue backfill, grouting and filling technology, total tailings cementing and filling, waste rock construction waste cementing and filling technology, and high-water filling technology [25].

The optimization of the ratio of grouting filling materials can not only improve the filling quality but also reduce the filling cost and bring great economic benefits to the coal mine. However, there are few studies on the ratio of separation grouting filling materials in coal mines in China, and the design of the ratio of separation grouting filling materials is relatively random, lacking certain scientific basis [26]. Orthogonal experiment is a scientific method to study and deal with multiple factors, and it has the advantages of "uniform dispersion and homogeneous comparison" and can obtain better results with fewer test times [27]. In this paper, the orthogonal test method is innovatively used to optimize the ratio of coal gangue separation grouting filling materials.

3.1. Test Materials and Methods. The basic characteristic of the orthogonal test model is to replace the comprehensive test with the partial test to understand the situation of the comprehensive test through the analysis of partial test results [28]. According to the number of factors in the experiment and the level of each factor, we select the appropriate orthogonal table to arrange the experiment and use the mathematical statistics method to process the data. This method can be convenient to find out the main factors that have a significant impact on the test index, and determine the factors that make the test index reach the best level.

The filling materials used in this experiment are cement, fly ash, and coal gangue. The cement is 325 ordinary Portland cement, and the fly ash is taken from the fly ash of Daizhuang coal mine power plant. The density is $2.24 \mathrm{t} / \mathrm{m}^{3}$, and the permeability coefficient is $3.3 \times 10^{5} \mathrm{~cm} / \mathrm{s}$. Coal gangue is taken from coal gangue (particle size $\leq 25 \mathrm{~mm}$ ) after secondary crushing in Daizhuang coal mine, the water content is $5 \%$, the density is $2.5 \mathrm{t} / \mathrm{m}^{3}$, and the permeability coefficient is $2.3 \times 10^{4} \mathrm{~cm} / \mathrm{s}$. A total of 9 groups of tests were carried out. The setting time, slump, stratification, and bleeding rate of the slurry were measured and recorded after the slurry stirred evenly. Three test blocks were poured into each group of tests, and the size of the test blocks was 
$(15 \times 15 \times 15) \mathrm{cm}^{3}$. After stripping the mold, the curing shall be carried out in a constant temperature curing box. The curing temperature is $22 \pm 1^{\circ} \mathrm{C}$, and the humidity is $\geq 90 \%$. After curing for 28 days, respectively, and reaching the specified age, the uniaxial compressive strength was measured by the YAW400 pressure testing machine, and the experimental results were included in the orthogonal analysis table.

3.2. Design of Orthogonal Experiment Scheme. By referring to relevant research experiences and combining with practical experience of coal mine grouting and filling engineering, this grouting and filling material ratio test is divided into three factors: cement content A (cement quality/mixture quality), ash and gangue ratio (fly ash: gangue) $\mathrm{B}$, and backfill concentration C. Through the analysis of these three factors, the orthogonal experiment of three factors and three levels is adopted in this study. The indexes to measure the performance of backfill are backfill pumpability and backfill strength. Backfill pumpability mainly includes initial setting time, degree of collapse, degree of layering, and bleeding rate. Therefore, the indexes of this test are setting time $\left(D_{1}\right)$, collapse degree $\left(D_{2}\right)$, laying-out degree $\left(D_{3}\right)$, bleeding rate $\left(D_{4}\right)$, and compressive strength of backfill $\left(D_{5}\right)(28 \mathrm{~d})$. The values of each factor are shown in Table 1.

According to the rule of the orthogonal test and combined with the actual situation, the $L_{9}$ (33) orthogonal table is selected to fill in the factors and levels in Table 2, and the specific conditions of each group of tests are listed. The experiment is carried out according to the test scheme (Table 2), and the measurement results are filled in Table 3.

3.3. The Test Results. Respectively, $D_{1}$ to $D_{5}$ were used as the investigation index to calculate the $K, k$, and $R$ values of each column in Table 2 , where $K_{i}$ (column $\left.j\right)=$ the sum of indicators corresponding to the number " $i$ " in column $j ; K_{i}(\operatorname{column} J)=$ the repeat number of " $i$ " in column $j ; R$ (column $j)=$ the difference between the maximum value and the minimum value of $k_{1}, k_{2}$, and $k_{3}$ in column $j . .$. The calculation results are shown in Tables 4-8.

\subsection{Result Analysis}

3.4.1. Range Analysis. Through the analysis of range $R_{1} \sim R_{5}$ in Tables 4-8, it can be seen that the range of various factors on backfill setting time is cement content, concentration, and gray-gangue ratio from the largest to the smallest. The range of backfill collapse was concentration, ash-gangue ratio, and cement content. The range of stratification degree and bleeding rate of backfill ranged from large to small were gray-gangue ratio, concentration, and cement content. The range of backfill strength from large to small is cement content, concentration, and gray-gangue ratio. It can be concluded as follows:

(1) The cement content is the main factor affecting the setting time and strength of backfill. This is mainly due to the hydrolyzation or hydration reaction of
TABLE 1: Orthogonal test factor level.

\begin{tabular}{lccc}
\hline Level & \multicolumn{3}{c}{ Factors } \\
& A (\%) & B & C (\%) \\
\hline 1 & 5 & $2: 1$ & 78 \\
2 & 10 & $1: 1$ & 72 \\
3 & 15 & $1: 2$ & 75 \\
\hline
\end{tabular}

TABLE 2: $L_{9}\left(3^{3}\right)$ orthogonal test design table of paste filling material.

\begin{tabular}{lcccc}
\hline \multirow{2}{*}{ Serial number } & \multicolumn{4}{c}{ Factors } \\
& $\mathrm{A}$ & $\mathrm{B}$ & $\mathrm{C}$ & $D_{i}$ (indicators) \\
\hline S1 & $1(5 \%)$ & $1(1: 0.5)$ & $1(78 \%)$ & - \\
S2 & $1(5 \%)$ & $2(1: 1)$ & $2(72 \%)$ & - \\
S3 & $1(5 \%)$ & $3(1: 2)$ & $3(75 \%)$ & - \\
S4 & $2(10 \%)$ & $1(1: 0.5)$ & $3(75 \%)$ & - \\
S5 & $2(10 \%)$ & $2(1: 1)$ & $1(78 \%)$ & - \\
S6 & $2(10 \%)$ & $3(1: 2)$ & $2(72 \%)$ & - \\
S7 & $3(15 \%)$ & $1(1: 0.5)$ & $2(72 \%)$ & - \\
S8 & $3(15 \%)$ & $2(1: 1)$ & $3(75 \%)$ & - \\
S9 & $3(15 \%)$ & $3(1: 2)$ & $1(78 \%)$ & - \\
\hline
\end{tabular}

cement clinker minerals in water, which generates $\mathrm{C}-\mathrm{S}-\mathrm{H}$ gel and $\mathrm{Ca}(\mathrm{OH})_{2}, \mathrm{C}_{3} \mathrm{AH}_{6}, \mathrm{AFt}$, and other products. These products have strong cementing properties, and in a certain way, they overlap and join with each other by various gravity forces to form the structure of cement stone and thus generate strength.

(2) The density of backfill is the main factor that affects the subsidence degree of backfill, and the proportion of fly ash and gangue directly affects the stratification degree and drainage rate of backfill. This is mainly caused by the particle size distribution between fly ash and coal gangue, namely, fine aggregate and coarse aggregate. In addition, the fly ash has a large specific surface area and a strong ability to absorb water, resulting in a certain secreting property of backfill.

3.4.2. Intuitionistic Analysis. Although range analysis can quantitatively determine the sensitivity of each factor to each performance index of backfill, it cannot see the change trend of each index with each factor. Taking each factor as the $\mathrm{x}$-coordinate and the average value of each index as the $y$ coordinate, the trend charts of factors and indicators are drawn, as shown in Figures 4-8.

As can be seen from Figures 4-8, the setting time of backfill gradually decreases with the increase of cement content. With the increase of backfill concentration, the collapse degree of backfill decreases, which is reflected in the reduced fluidity, and the appropriate increase of fly ash content is conducive to the improvement of backfill fluidity. With the increase of coal gangue, the stratification degree and bleeding rate of backfill are greatly reduced, but the change of concentration has little influence on this, indicating that the reasonable control of the ratio of fly ash to gangue (this test is $1: 2$ ) is conducive to the reduction of the stratification degree and bleeding rate of backfill and the 
TABLE 3: Results of the $L_{9}\left(3^{3}\right)$ orthogonal test.

\begin{tabular}{lccccc}
\hline $\begin{array}{l}\text { Serial number } \\
S i\end{array}$ & $\begin{array}{c}\text { Setting time } D_{1} \\
(\mathrm{~h})\end{array}$ & $\begin{array}{c}\text { Collapse degree } D_{2} \\
\mathrm{~cm}\end{array}$ & $\begin{array}{c}\text { Laying-out degree } D_{3} \\
(\mathrm{~mm})\end{array}$ & $\begin{array}{c}\text { Bleeding rate } D_{4} \\
(\%)\end{array}$ & $\begin{array}{c}\text { Compressive strength of backfill } D_{5} \\
(\mathrm{MPa})\end{array}$ \\
\hline S1 & 8.5 & 11.5 & 30.1 & 3.5 & 2.23 \\
S2 & 7.5 & 18.7 & 5 & 1.7 & 0.97 \\
S3 & 6.8 & 7 & 1 & 0.94 & 1.1 \\
S4 & 6.5 & 21.3 & 35 & 2.7 & 2.11 \\
S5 & 6 & 9 & 4 & 1.62 & 3.38 \\
S6 & 6.7 & 20.5 & 12 & 2.03 & 3.07 \\
S7 & 5.2 & 19.2 & 20 & 2.1 & 1.97 \\
S8 & 5 & 20.1 & 11 & 1.76 & 2.9 \\
S9 & 5.5 & 8.3 & 3 & 2.03 & 4.07 \\
\hline
\end{tabular}

TABLE 4: Results of the setting time $\left(D_{1}\right)$ of paste filling.

\begin{tabular}{cccc}
\hline & $\mathrm{A}$ & $\mathrm{B}$ & $\mathrm{C}$ \\
\hline$k_{1}$ & 7.7 & 6.7335 & 6.6665 \\
$k_{2}$ & 6.4 & 6.25 & 6.5835 \\
$k_{3}$ & 5.25 & 6.3665 & 6.1 \\
$R_{1}$ & 2.45 & 0.4835 & 0.5665 \\
\hline
\end{tabular}

TABLE 5: Results of the collapsed slump $\left(D_{2}\right)$ of paste filling.

\begin{tabular}{cccc}
\hline & $\mathrm{A}$ & $\mathrm{B}$ & $\mathrm{C}$ \\
\hline$k_{1}$ & 12.4 & 17.333 & 9.6 \\
$k_{2}$ & 16.933 & 15.933 & 19.467 \\
$k_{3}$ & 15.867 & 11.933 & 16.133 \\
$R_{2}$ & 3.467 & 5.4 & 9.867 \\
\hline
\end{tabular}

Table 6: Results of the segregation degree $\left(D_{3}\right)$ of paste filling.

\begin{tabular}{lccc}
\hline & $\mathrm{A}$ & $\mathrm{B}$ & $\mathrm{C}$ \\
\hline$k_{1}$ & 12.033 & 28.367 & 12.367 \\
$k_{2}$ & 17 & 6.667 & 12.333 \\
$k_{3}$ & 11.333 & 5.333 & 5.667 \\
$R_{3}$ & 5.667 & 23.034 & 6.701 \\
\hline
\end{tabular}

TABLE 7: Results of the bleeding ratio $\left(D_{4}\right)$ of paste filling.

\begin{tabular}{lccc}
\hline & $\mathrm{A}$ & $\mathrm{B}$ & $\mathrm{C}$ \\
\hline$k_{1}$ & 2.047 & 2.767 & 2.383 \\
$k_{2}$ & 2.117 & 1.693 & 1.943 \\
$k_{3}$ & 1.963 & 1.667 & 1.8 \\
$R_{4}$ & 0.154 & 1.1 & 0.583 \\
\hline
\end{tabular}

TABLE 8: Results of the compressive strength $\left(D_{5}\right)$ of paste filling.

\begin{tabular}{lccc}
\hline & $\mathrm{A}$ & $\mathrm{B}$ & $\mathrm{C}$ \\
\hline$k_{1}$ & 1.433 & 2.103 & 3.227 \\
$k_{2}$ & 2.853 & 2.417 & 2.003 \\
$k_{3}$ & 2.98 & 2.747 & 2.037 \\
$R_{5}$ & 1.547 & 0.644 & 1.224 \\
\hline
\end{tabular}

pumping of backfill. The strength of backfill increases with the increase of cement content, and the concentration also has a certain influence on the strength of backfill. The strength of backfill increases with the increase of the concentration, but the increase is not large, about 7\%.

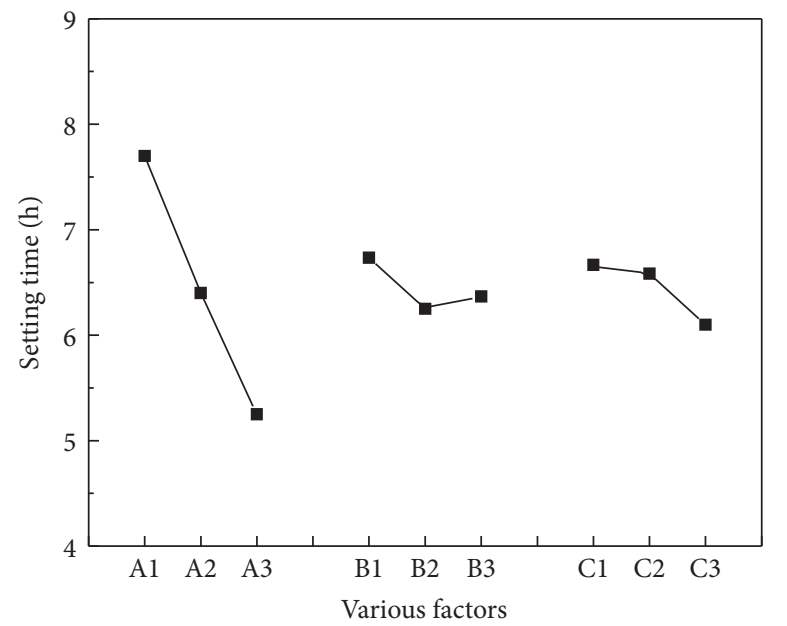

FIgURE 4: The tendency of compressive strength and factor level of paste filling.

3.4.3. Ratio Optimization Results. According to the previous range analysis and intuitionistic analysis, in accordance with the principle of Jinchuan company grouting filling material proportioning design, the parameters of pumping filling body are commonly 4 to 6 hours for setting time, slump $18 \sim 22 \mathrm{~cm}, 2 \mathrm{~cm}$ or less for layering degree, $\leq 2 \%$ for bleeding rate, and $\sigma_{28 \mathrm{~d}} \geq 1.5 \mathrm{MPa}$. It can be seen that (1) for $D_{1}$, by comparing the experimental factor, the optimal matching is $\mathrm{A}(3), \mathrm{B}(2)$, and $\mathrm{C}(3)$; (2) for $\mathrm{D}_{2}, \mathrm{~A}(2), \mathrm{B}(1)$, and $\mathrm{C}(2)$ are selected as the optimal matches; (3) for $D_{3}, A(3), B(3)$, and $\mathrm{C}(3)$ are selected as the optimal matches; (4) for $D_{4}, \mathrm{~A}(3)$, $\mathrm{B}(3)$, and $\mathrm{C}(3)$ are selected as the optimal coordination; and (5) for $D_{5}, \mathrm{~A}(3), \mathrm{B}(3)$, and $\mathrm{C}(1)$ are selected as the optimal coordination. Considering 5 indexes comprehensively, the optimal ratio of the backfill material test is $\mathrm{A}(3), \mathrm{B}(3)$, and $\mathrm{C}(3)$. In other words, the cement content of cementing materials is $15 \%$, the fly ash is $1: 2$ for coal gangue, and the backfill concentration is $75 \%$ (i.e., the cement: fly ash: coal gangue is $1: 1.33: 2.66$ ). The experiment measured that the setting time of backfill was $6 \mathrm{~h}$ and the collapse degree was $21.5 \mathrm{~cm}$ under the condition of the ratio. The stratification degree was $1.8 \mathrm{~cm}$. The bleeding rate was $1.5 \%$. $\sigma_{28 \mathrm{~d}}=4.7 \mathrm{MPa}$, which fully conforms to the design principle of grouting filling material ratio of Jinchuan company. 


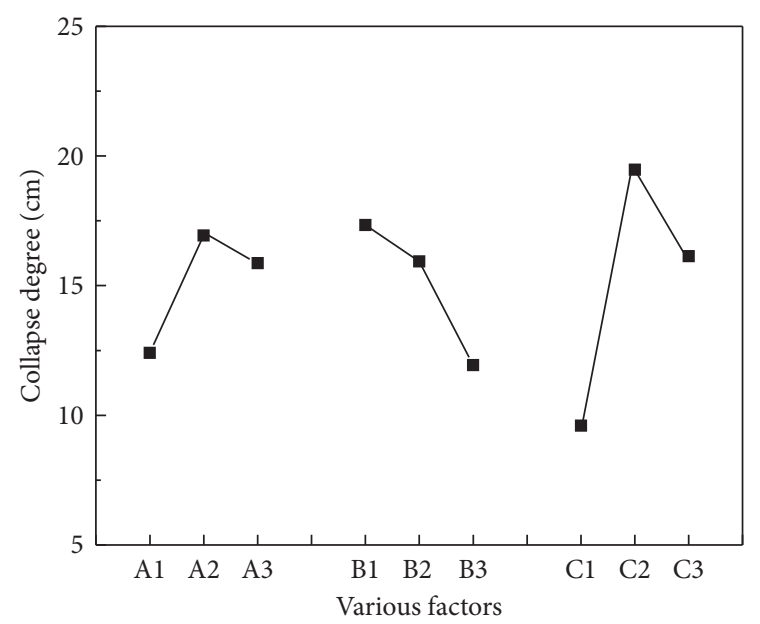

FIGURE 5: The tendency of collapsed slump and factor level of paste filling.

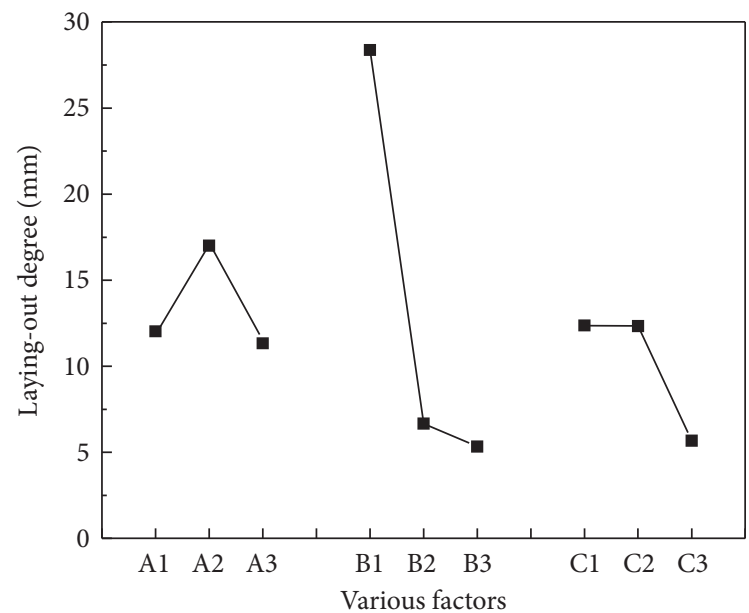

FIgURE 6: The tendency of segregation degree and factor level of paste filling.

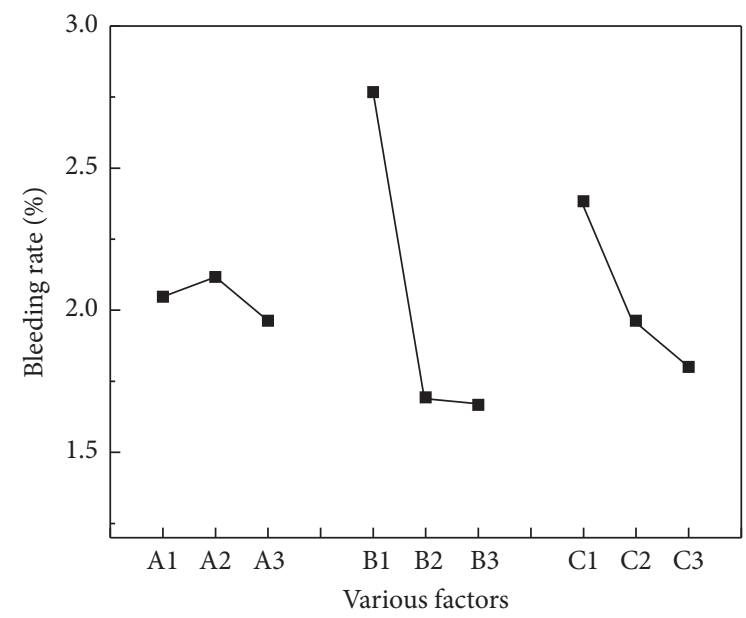

Figure 7: The tendency of bleeding ratio and factor level of paste filling.

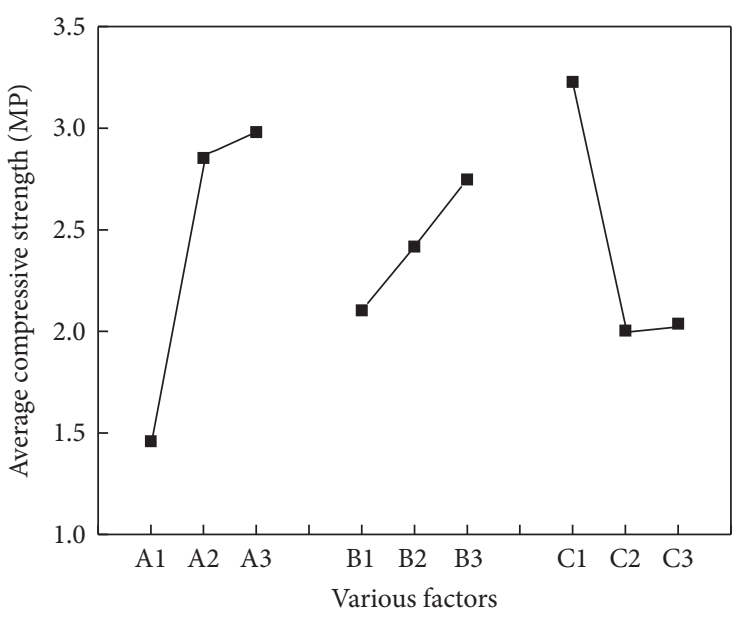

FIGURE 8: The tendency of compressive strength and factor level of paste filling.

\section{Study on a New Type of Pocket Assay Grouting Technology}

In order to effectively prevent the occurrence of rock burst under superthick conglomerate, this study puts forward a kind of pocket layer reinforcement technology under superthick conglomerate based on the previous research results and the practice of separation grouting. The testing site is at $1410 \#$ working face of Huafeng coal mine, and holes are drilled along the inclined direction layout where it is predicted as the maximum height of the abscission layer. It means that the layout of borehole is along the direction of district raise of the mining area and the rectangle or triangle arrangement is $145 \mathrm{~m}$ from starting cut of 1410 face. The spacing of boreholes generally is $25 \mathrm{~mm}$, the depth of hole is $982 \mathrm{~m}$, and the diameter of hole is $240 \mathrm{~mm}$ to $300 \mathrm{~mm}$. From bottom to top, the stratigraphic structure of the worksite in the test area is siltstone with a direct top of $2.6 \mathrm{~m}$, a fine medium sandstone with a thickness of about $20 \mathrm{~m}$ at the old top, and a superthick conglomerate with an actual thickness of $800 \mathrm{~m}$. The layer separation reinforcement material mixes the fly ash, cement, admixture, and water according to a certain proportion with slurry mass concentration of $60 \%$ $75 \%$ which is a kind of paste-like backfill material. The grouting pressure was maintained at $0.4 \sim 0.6 \mathrm{MPa}$, the grouting volume per meter was about $120 \sim 130 \mathrm{~L}$, and the grouting flow was $50 \sim 65 \mathrm{~L} / \mathrm{min}$. The way of grouting is bottom up, and the next section of grouting can only be carried out after the last section of pocket grouting to the design amount. The amount of the first grouting was $70 \%$ of the designed amount, and the rest of the grouting was finished in two times every 30 minutes.

4.1. Project Summary. The 1410 working face of Huafeng mine was selected in the study area, with a vertical mining depth of $1140 \mathrm{~m}$ and a superthick conglomerate thickness of $500-800 \mathrm{~m}$ over the coal seam. $4 \#$ and $6 \#$ coal in the front group are the main coal seams. The average dip angle of the coal strata is $33^{\circ}$, the average thickness of the coal seam is 


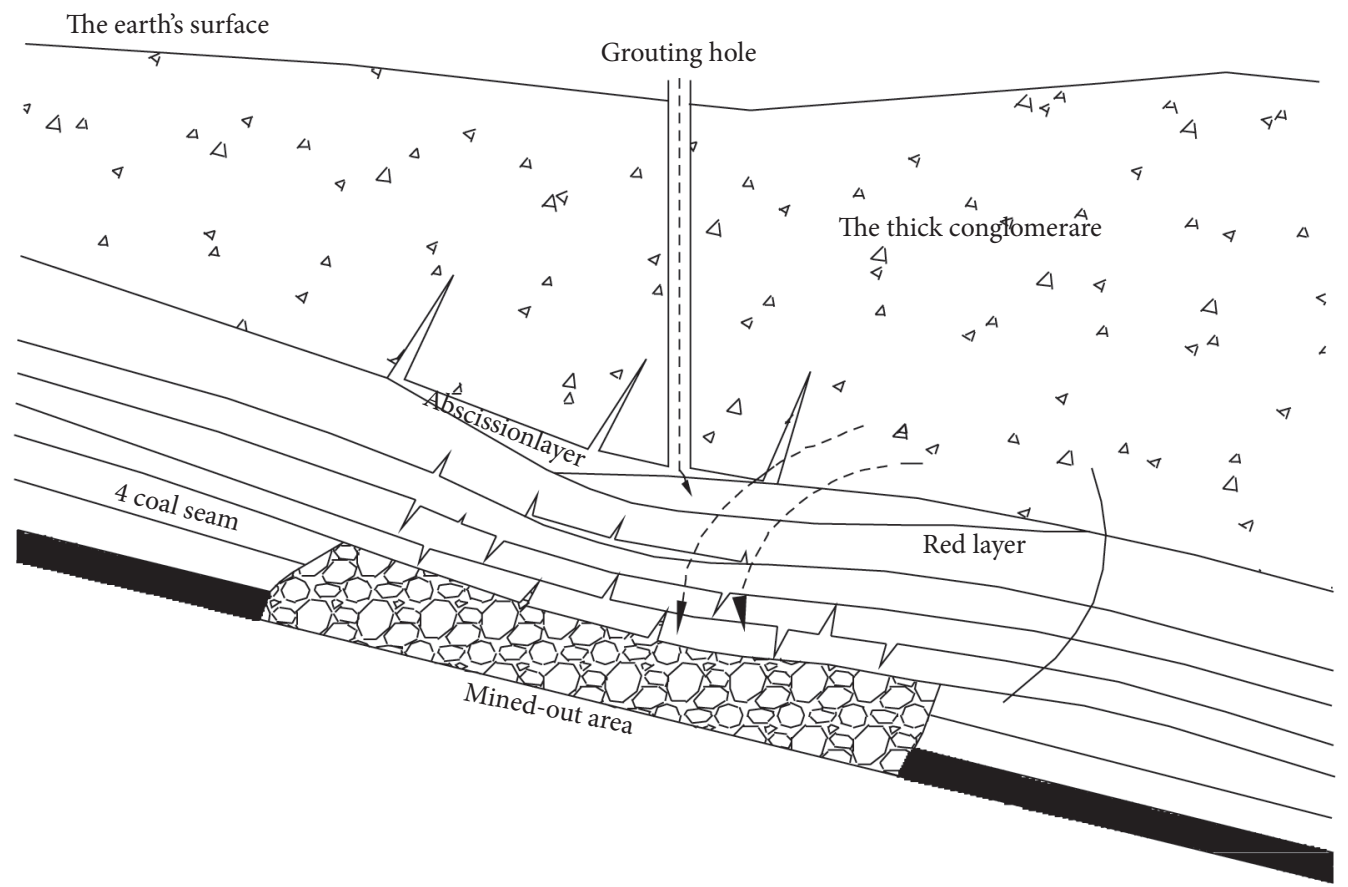

Figure 9: Diagram of separation layer plane and drilling hole oblique.

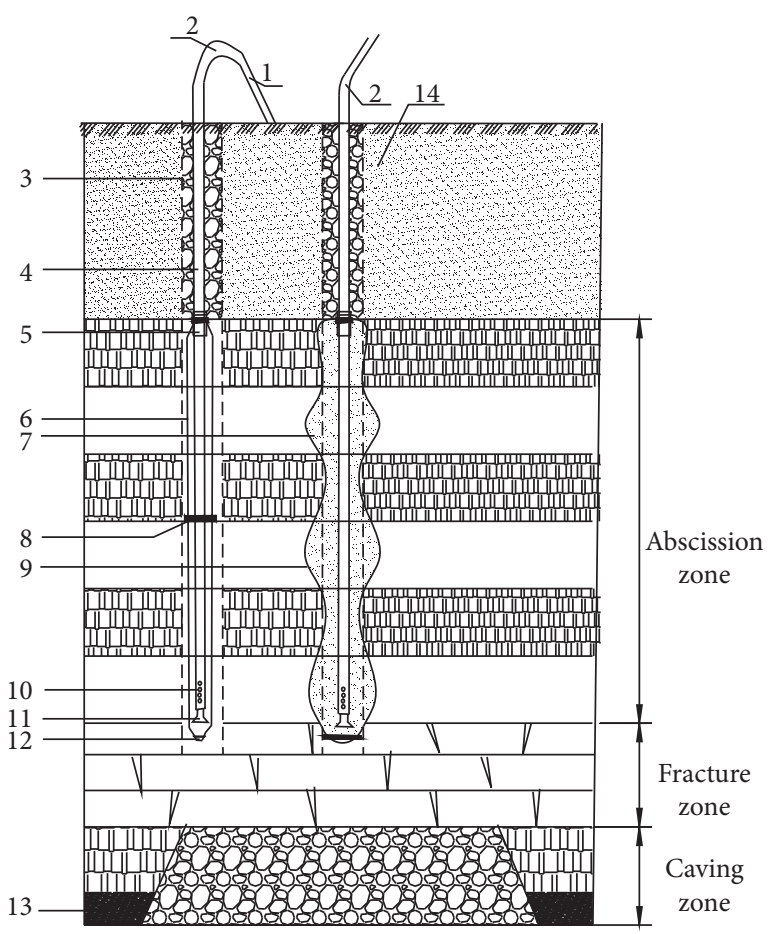

Figure 10: Pocket layer reinforcing process. In the figure, the numbers represent the following parts: (1) high-pressure hose, (2) grouting pipe bend, (3) the grouting hole, (4) grouting steel pipe, (5) plastic ring, (6) nylon pouch, (7) material slurry, (8) the rubber aprons, (9) pocket inflation, (10) perforated grouting pipe, (11) rubber plug, (12) wire head, (13) coal seam, and (14) surface soil layer.

$6.41 \mathrm{~m}$, and the average thickness of the coal seam is $2.6 \mathrm{~m}$ above the roof. The hard old roof is formed by four layers of middle sandstone with a thickness of about $4-5 \mathrm{~m}$ and two layers of siltstone with a thickness of about 5-6 m. In addition, about 150 200 $\mathrm{m}$ above the 4\# coal, a conglomerate layer with a thickness of 500 800 $\mathrm{m}$ is existed, which is the main key layer. The conglomerate layer is hard and has good integrity. The field monitoring data show that the $4 \#$ coal has a serious bursting liability and a strong bursting pressure destruction capacity, causing the damage of supports, roof caving, roadway blockage, and even casualties on multiple working faces. The occurrence of rock burst has also caused surface subsidence. On the surface directly above the working face 1410 of Huafeng mine, there is an obvious subsidence area, and a huge porphyritic fissure with a length of several hundred meters, a width of $2 \sim 3 \mathrm{~m}$, and a depth of $50 \sim 80 \mathrm{~m}$ is formed through the surface.

4.2. Determination of Separation and Borehole Location. According to theoretical research, the laboratory test, and field experience, the diffusion radius of the grouting hole is generally around $30 \mathrm{~m}$. However, considering the actual filling effect, it is known from field investigation of several mines that the grouting radius is generally $160 \mathrm{~m} \sim 250 \mathrm{~m}$ along the coal seam strike and $130 \mathrm{~m} \sim 200 \mathrm{~m}$ along the coal seam dip. For nearhorizontal coal-measure strata, the separation grouting hole is generally arranged in the center along the inclined direction, and the hole spacing along the strike direction is $30 \sim 50 \mathrm{~m}$. For coal-measure strata with a large dip angle, the drilling hole should be located in the district raise direction of the mining area and the predicted separation height is the highest. The hole spacing along the strike direction is $20 \sim 40 \mathrm{~m}$. During the grouting, the slurry will first fill the separation space in the part of the hill and then fill the center of the basin.

According to the calculation method of the height of water-conducting fracture zone in the coal mine water prevention and control regulations, the development height of 
fracture zone is $126.75 \mathrm{~m}$ when fully mechanized caving mining of the fourth coal seam in Huafeng coal mine is calculated. When the working face is pushed to $250 \mathrm{~m}$, the separation height is $158 \mathrm{~m}>126.75 \mathrm{~m}$, and there is a $15.6 \mathrm{~m}$ mudstone below as a good water-proof layer, which can be used for separation grouting. Therefore, the separation grouting is carried out when the working face is pushed to $250 \mathrm{~m} \sim 290 \mathrm{~m}$, and the separation volume at $290 \mathrm{~m}$ reaches the maximum of $3.5 \mathrm{~m}$, and the separation span also reaches the maximum of $85 \mathrm{~m}$, which is the best period for the separation grouting. The grouting hole should be arranged in the direction of the mining area to the top of the hill, $145 \mathrm{~m}$ away from the cut hole, and the depth of the drilling hole is $982 \mathrm{~m}$. During the grouting, the slurry will first fill the separation space of part of the hill, and then fill the center of the basin until the whole separation is filled, as shown in Figure 9.

4.3. Grouting System and Main Equipment. The layout and area of the grouting system are mainly related to the type, quantity, and selected grouting materials of the equipment. As shown in Figure 10, the main equipment of grouting system is as follows: grouting pump, mixer, pressure fan, measuring instrument, pipeline, power supply system, mixing tank, grouting material storage place, etc. The equipment in the station should be arranged neatly and compactly according to the purpose of use, which is convenient for operation and maintenance. The grouting system should be as close as possible to the grouting point, so that the grouting line is short and less bent, so as to reduce the loss of the grouting line and the pressure head [29].

The main large equipment of the grouting system is high-pressure grouting pump. A 3dZB-80/35 grouting pump produced by Lanzhou Xibao Petroleum Machinery Equipment Co., Ltd. is selected. The performance parameters of the 3DZB-80/35 grouting pump are shown in Table 9.

4.4. Separation Grouting Reinforcement Process. The pockettype separation reinforcement process under superthick conglomerate includes seven steps: construction preparation, drilling hole, grouting pipe and pocket making, grouting pipe and pocket binding and hole sinking, slurry preparation and grouting, drawing grouting pipe and backfilling through drilling hole, and flushing grouting pipe, as follows:

(1) Construction preparation: cement and fly ash are, respectively, screened to ensure that they are not caked and stored in the fine silo. Water, cement, fly ash, and admixture are prepared based on the designed proportion. The test area is leveled off, and the grouting hole is lofted by the measuring equipment such as total station or GPS. Generally, grouting holes are arranged along the trend and tendency direction of the stope face and rectangle or triangle layout, spacing generally $10 \sim 30 \mathrm{~m}$. The specific layout shall be determined according to the actual situation on site. Mixer equipment, highpressure grouting pump, drilling rig, and other equipment come in and install in place.
(2) Drilling: high-power engineering geological drilling rig $(>58 \mathrm{~kW})$ or DZ60KS type vibration hammer sinking machine is used to drill to the design depth. The hole diameter is $240-300 \mathrm{~mm}$, and the drilling inclination is less than $1 \%$.

(3) Making the grouting pipe and pocket: generally, the grouting pipe is made of steel pipe with an outer diameter of $40 \mathrm{~mm}$ and an inner diameter of $35 \mathrm{~mm}$. The length of the grouting pipe is generally greater than the design depth of the drilling hole, which is $400 \mathrm{~mm} \sim 600 \mathrm{~mm}$. There is a bend at the upper end of the grouting pipe, connecting the high-pressure rubber hose to lay a plum blossom shaped grouting hole in the place $300 \sim 400 \mathrm{~mm}$ away from the bottom of the steel pipe. The hole size is $8 \sim 10 \mathrm{~mm}$, and the number is $3 \sim 4$ in each row. A total of $6 \sim 8$ circular holes are drilled to facilitate the flow of slurry out of the flowered pipe. The pocket is seamless woven with nylon fiber, $180 \mathrm{~g} \sim 220 \mathrm{~g} / \mathrm{m} 2$ in size, $500 \sim 600 \mathrm{~mm}$ in diameter, and $600 \sim 700 \mathrm{~mm}$ longer than the design hole.

(4) Tying the grouting pipe with the pocket and lower the hole: first, we cover the nylon pocket with the bottom up to the outside of the grouting pipe, tie the bottom end of the pocket with no. 14 thin wire, then fold the bottom end back $250 \sim 300 \mathrm{~mm}$, and tie the bottom end with no. 14 thin wire, in order to prevent the slurry leakage. From the bottom of the pocket every 0.8 to $1.2 \mathrm{~m}$, we use rubber cover or no. 11 wire to tie the pocket on the grouting tube. At the top of the pocket, the pocket is tied with a plastic ring to ensure that the ring can slide on the grouting tube. After the drilling hole is cleaned, the grouting pipe with pocket is slowly put into the drilling hole by hanging the drilling machine. When the pocket reaches the design height, that is, the separation zone, it will stop to lower down.

(5) Mixing and grouting: the prepared cement and fly ash are put through the standard screen to prevent the cement and fly ash from agglomerating and affecting the quality of the slurry. Each material is weighed according to the design proportion, and we put it into the blender to mix, and the mixing time is no less than $90 \mathrm{~s}$. After the mixing is completed, the slurry enters the high-pressure grouting pump. Driven by the hb6-3 high-pressure grouting pump, the slurry is injected into the nylon pocket through the ground pumping pipe, high-pressure rubber hose, grouting pipe elbow, and grouting pipe.

(6) Pulling out the grouting pipe: after the grouting amount of the pocket reaches the design requirements, and when the grouting amount and the grouting pressure are basically the same as the design requirements, the pocket has been fully expanded. At this time, the YJ.50 molding machine can be used to slowly pull out the grouting pipe. It is worth noting that the drawing speed and grouting speed should be 
TABLE 9: DZB-80/35 performance parameters of the grouting pump.

\begin{tabular}{|c|c|c|c|c|c|}
\hline Gearbox grade & $\mathrm{I}$ & II & III & IV & $\mathrm{V}$ \\
\hline The pump speed $\left(\mathrm{min}^{-1}\right)$ & 40 & 68.8 & 111.8 & 163.8 & 240 \\
\hline Pressure (MPa) & 24 & 14 & 8.6 & 5.88 & 4 \\
\hline Theory of displacement $\left(\mathrm{m}^{3} / \mathrm{h}\right)$ & 13.4 & 23.1 & 37 & 55 & 80 \\
\hline Water pump power & $90 \mathrm{~kW}$ & \multicolumn{2}{|c|}{ Plunger diameter } & \multicolumn{2}{|c|}{$\varphi 115$} \\
\hline Motor model & Y315M-4 & \multicolumn{2}{|c|}{ Synchronous speed } & \multicolumn{2}{|c|}{$1500 \mathrm{r} / \mathrm{min}$} \\
\hline Power & $132 \mathrm{~kW}$ & \multicolumn{2}{|c|}{ Work speed } & \multicolumn{2}{|c|}{$1480 \mathrm{r} / \mathrm{min}$} \\
\hline
\end{tabular}

coordinated at this time and must be controlled at $0.5 \sim 0.8 \mathrm{~m} / \mathrm{min}$, and the grouting pressure should be maintained at $0.4 \sim 0.6 \mathrm{MPa}$. After the grouting steel pipe is completely pulled out, sand and gravel are used to backfill the upper empty hole, and the ground is vibrated and compacted at the same time.

(7) Flushing the grouting steel pipe and moving it to the next hole for the next cycle: in order to improve work efficiency, multiple grouting pumps can be used in parallel operation to shorten the construction period.

4.5. Effect of Grouting in Separate Stratum. According to the industrial test data, the technical indicators of pocket layered reinforcement materials are as follows: slurry apparent density is $1.4-\sim 1.6 \mathrm{~g} / \mathrm{cm}^{3}$, mass concentration is $60 \sim 70 \%$, viscosity is $32 \sim 35 \mathrm{~s}$, bleeding rate is $0 \sim 3 \%$, collapse degree is $22 \sim 26 \mathrm{~cm}$, and initial setting time is less than $4 \mathrm{~h}$. Uniaxial compression strength $\sigma_{8 \mathrm{~h}}>0.5 \mathrm{MPa}$ and $\sigma_{7 \mathrm{~d}}>2.5 \mathrm{MPa}$. Different from the traditional separation grouting process, the pocket-type layer separation reinforcement technology, in the early stage of coal mining, lateral and longitudinal reinforcement can be carried out in the area prone to separation under the key layer, make the soft rock in the separation zone have a certain flexural, shear, and compressive strength, and change the traditional passive postseparation grouting to active separation reinforcement. To control surface subsidence and prevent coal seam bursting, it is necessary to restrict the development of separation layers and ensure that the key layers are not broken. Through the isolation function of the pocket, the slurry will not leak and will spread to the working face through cracks, polluting the environment. In terms of the cost control of grouting materials, the total grouting amount for each drill hole is about $18.84 \mathrm{t}$ based on the slurry specific gravity of $1.5 \mathrm{t} / \mathrm{m}^{3}$, the pocket diameter of $400 \mathrm{~mm}$, and the pocket design height of $100 \mathrm{~m}$. According to the grouting material cost of about 150 yuan/t, the grouting material cost for single hole drilling is about 2836 yuan. Generally, the strike length of stope is $1000 \mathrm{~m}$, and the dip length is $100 \mathrm{~m}$. According to the grouting hole spacing of $20 \mathrm{~m}$, the total number of holes to be drilled is about 200 , and the total cost is about 567, 200 yuan. If the bulk density of the coal seam is $1.37 \mathrm{t} / \mathrm{m}^{3}$ and the mineable thickness of the coal seam is $3 \mathrm{~m}$, then the total mineable coal on this surface is $411,000 \mathrm{t}$, and the cost of grouting material for a total ton of coal is only 1.38 yuan/t. Therefore, the separation reinforcement technology has certain economic, social, and environmental benefits and has certain promotion value.

\section{Conclusion}

Using the occurrence of wide range separation after mining coal seam under superthick conglomerate, the overburden separation grouting can not only slow down the surface subsidence but also inhibit the occurrence of underground rock burst.

Through the establishment of the stress model of the separation grouting backfill, it is found that the separation grouting filling technology can effectively limit the conglomerate bending settlement, inhibit the concentration and accumulation of stress in the conglomerate, thus improve the force source structure of the rock burst, and play a role in slowing down the surface subsidence and preventing the impact disaster.

The optimization test of material ratio showed that increasing the cement content can shorten the setting time and increase the strength of backfill. The collapse degree of backfill, namely, the fluidity, is realized mainly by reducing the backfill concentration. An appropriate amount of fly ash can improve the fluidity of backfill. However, with the increase of fly ash, the degree of stratification and the water secretion rate both increases. Therefore, fly ash content should be strictly controlled in the actual production. Under the conditions of this test, it is concluded that the optimal proportion of coal gangue grouting filling materials is cement: fly ash: coal gangue $1: 2.22: 4.44$, and the concentration is $75 \%$. Under the conditions of this proportion, the pumpability and strength of backfill are the best.

In this paper, a kind of pocket assay grouting technology is proposed, which can be used for transverse extrusion and longitudinal reinforcement in the layer separation area, so that the weak rock in the layer separation area has a certain flexural, shear, and compressive strength, and the traditional passive postseparation grouting can be changed into active layer separation reinforcement. This technology can prevent slurry leakage, protect the environment, improve the grouting efficiency, reduce the grouting cost, and realize safe, efficient, and green coal mining.

\section{Data Availability}

The data used to support the findings of this study are available from the corresponding author upon request.

\section{Conflicts of Interest}

The authors declare no conflicts of interest. 


\section{Acknowledgments}

The work referenced in this paper was supported by funding from the National Natural Science Foundation of China (no. 41601593) and the Doctoral Scientific Research Foundation of Shandong Technology and Business University, China (BS202005).

\section{References}

[1] P. Konicek, K. Soucek, L. Stas, and R. Singh, "Long-hole destress blasting for rockburst control during deep underground coal mining," International Journal of Rock Mechanics and Mining Sciences, vol. 61, pp. 141-153, 2013.

[2] S. Zhang, Y. Li, B. Shen, X. Sun, and L. Gao, "Effective evaluation of pressure relief drilling for reducing rock bursts and its application in underground coal mines," International Journal of Rock Mechanics and Mining Sciences, vol. 114, pp. 7-16, 2019.

[3] W. Guo, Y. Li, D. Yin, S. Zhang, and X. Sun, "Mechanisms of rock burst in hard and thick upper strata and rock-burst controlling technology," Arabian Journal of Geosciences, vol. 9, no. 10, pp. 1-11, 2016.

[4] Z. Xuejun, S. Naiwei, W. Zhongju, and W. Qingbiao, "Preventing and minimizing mining disasters through grouting," Journal of Performance of Constructed Facilities, vol. 33, no. 5, Article ID 04019056, 2019.

[5] H. Wang, S. Xue, R. Shi, Y. Jiang, W. Gong, and L. Mao, "Investigation of fault displacement evolution during extraction in longwall panel in an underground coal mine," Rock Mechanics and Rock Engineering, vol. 53, pp. 1809-1826, 2019.

[6] H. Wang, R. Shi, D. Deng, Y. Jiang, G. Wang, and W. Gong, "Characteristic of stress evolution on fault surface and coal bursts mechanism during the extraction of longwall face in Yima mining area, China," Journal of Structural Geology, vol. 136, Article ID 104071, 2020.

[7] H. Gui, S. Tong, W. Qiu, and M. Lin, "Research on preventive technologies for bed-separation water hazard in China coal mines," Applied Water Science, vol. 8, no. 1, 2018.

[8] J.-C. Wang, F.-X. Jiang, X.-J. Meng, X.-Y. Wang, S.-T. Zhu, and Y. Feng, "Mechanism of rock burst occurrence in specially thick coal seam with rock parting," Rock Mechanics and Rock Engineering, vol. 49, no. 5, pp. 1953-1965, 2016.

[9] W. Guo, Y. Li, S. Zhang, C. Lu, and J. Zhao, "Surface movement characteristics and control under the influence of highstand thick-hard strata," Journal of Geotechnical and Geoenvironmental Engineering, vol. 19, pp. 6292-6303, 2014.

[10] S. Chen, D. Yin, F. Cao, Y. Liu, and K. Ren, "An overview of integrated surface subsidence-reducing technology in mining areas of China," Natural Hazards, vol. 81, no. 2, pp. 1129-1145, 2016.

[11] H. Ma, W. Sui, and J. Ni, "Environmentally sustainable mining: a case study on surface subsidence control of grouting into overburden," Environmental Earth Sciences, vol. 78, no. 10, 2019.

[12] D. Xuan, J. Xu, B. Wang, and H. Teng, "Borehole investigation of the effectiveness of grout injection technology on coal mine subsidence control," Rock Mechanics and Rock Engineering, vol. 48, no. 6, pp. 2435-2445, 2015.

[13] S. Baotang and P. Brett, "Investigation of overburden behaviour for grout injection to control mine subsidence," International Journal of Mining Science and Technology, vol. 24, no. 3, pp. 317-323, 2014.
[14] Y. Li, S. Zhang, Z. Wen et al., "Energy conversion and fragment distribution characteristics of coal sample under uniaxial cyclic loading," Journal of China Coal Society, vol. 44, no. 5, pp. 1411-1420, 2019.

[15] Y. Tai, H. Xia, X. Meng, and T. Kuang, "Failure mechanism of the large-section roadway under mined zones in the ultrathick coal seam and its control technology," Energy Science \& Engineering, vol. 8, no. 4, pp. 999-1014, 2020.

[16] W. Zhu, S. Yu, and J. Xu, "Influence of the elastic dilatation of mining-induced unloading rock mass on the development of bed separation," Energies, vol. 11, no. 4, 785 pages, 2018.

[17] H. Liu, B. Yu, J. Liu, and T. Wang, "Investigation of impact rock burst induced by energy released from hard rock fractures," Arabian Journal of Geosciences, vol. 12, no. 12, p. 381, 2019.

[18] Z. Yang, C. Liu, H. Zhu, F. Xie, L. Dou, and J. Chen, "Mechanism of rock burst caused by fracture of key strata during irregular working face mining and its prevention methods," International Journal of Mining Science and Technology, vol. 29, no. 6, pp. 889-897, 2019.

[19] Q. Wu, L. Jiang, Q. Wu, Y. Xue, and B. Gong, "A study on the law of overlying strata migration and separation space evolution under hard and thick strata in underground coal mining by similar simulation," DYNA-Ingeniería e Industria, vol. 94, no. 2, pp. 175-181, 2018.

[20] L. Jiang, Q. Wu, Q. Wu et al., "Fracture failure analysis of hard and thick key layer and its dynamic response characteristics," Engineering Failure Analysis, vol. 98, pp. 118-130, 2019.

[21] S. Kumar, G. Singh, and S. K. Mohapatra, "An assessment of the physical, mineral, and rheological properties of fly ash for stowing in coal mines," Energy Sources, Part A: Recovery, Utilization, and Environmental Effects, vol. 38, no. 20, pp. 2955-2962, 2016.

[22] A. Bouaissi, L. Y. Li, L. M. Moga, I. G. Sandu, M. M. A. B. Abdullah, and A. V. Sandu, "A review on fly ash as a raw cementitious material for geopolymer concrete," Revista de Chimie, vol. 69, no. 7, pp. 1661-1667, 2018.

[23] G. Sang, D. Elsworth, X. Miao, X. Mao, and J. Wang, "Numerical study of a stress dependent triple porosity model for shale gas reservoirs accommodating gas diffusion in kerogen," Journal of Natural Gas Science and Engineering, vol. 32, pp. 423-438, 2016.

[24] R. Rani and M. K. Jain, "Coal combustion product: nonhazardous material for mine fill," Environmental Quality Management, vol. 25, no. 4, pp. 107-119, 2016.

[25] J. Yang, B. Yang, and M. Yu, "Pressure study on pipe transportation associated with cemented coal gangue fly-ash backfill slurry," Applied Sciences, vol. 9, no. 3, 512 pages, 2019.

[26] L. Jin, W. Sui, and J. Xiong, "Experimental investigation on chemical grouting in a permeated fracture replica with different roughness," Applied Sciences, vol. 9, no. 13, 2762 pages, 2019.

[27] W. Sui, J. Liu, W. Hu, J. Qi, and K. Zhan, "Experimental investigation on sealing efficiency of chemical grouting in rock fracture with flowing water," Tunnelling and Underground Space Technology, vol. 50, pp. 239-249, 2015.

[28] Z. Jinpeng, L. Limin, Z. Futao, and C. Junzhi, "Development and application of new composite grouting material for sealing groundwater inflow and reinforcing wall rock in deep mine," Scientific Reports, vol. 8, no. 1, pp. 1-11, 2018.

[29] X. Hao, L. Yuan, Y. Li et al., "Lateral deformation characteristics of coal with bump tendency based on uniaxial compression experiment," Journal of China University of Mining and Technology, vol. 47, no. 1, pp. 130-136, 2018. 